\title{
THE FEMALE OF INOCELLIA PILICORNIS CARP. (NEUROPTERA: INOCELLIIDAE) ${ }^{1}$
}

\author{
By F. M. Carpenter \\ Harvard University
}

The snakefly, Inocellia pilicornis Carpenter, was described in 1959 (Psyche, 65:56-58) from three males collected in the states of Nuevo Leon and Tamaulipas, Mexico. These males were unique among known Raphidiodea in possessing moniliform antennae, their segments bearing long radiating setae, arranged in a definite pattern. In July, 1960, Dr. H. F. Howden, who collected one of the males of the original set, found the first known female of this species, along with another male, very near the type locality. It now turns out that the female also has moniliform antennae, but the hair covering of the antennae, although distinctly different from that of other species, is not as similar to that of the male of pilicornis as might be expected.

The color markings of the female are like those of the male type, except that the median white marks on the meso- and metanotum and the abdominal tergites are in the form of patches instead of a continuous stripe. The forewing is $6.8 \mathrm{~mm}$. long and $\mathrm{r} .8 \mathrm{~mm}$. wide; the

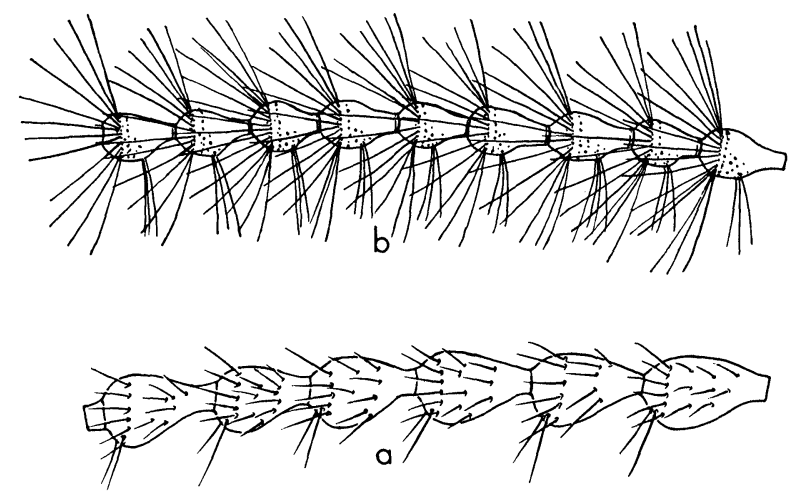

FIGURE 1. Portions of antennae of Inocellia pilicornis Carp. a, female, x 140 (specimen from Chipinguy Mesa); b, male, x 55 (holotype).

pterostigma, having a maximum length of $\mathrm{I} \mathrm{mm}$. and a width of a little less than $.5 \mathrm{~mm}$., is relatively shorter than in the male. The wing venation is like that of the holotype, illustrated in my account

\footnotetext{
${ }^{1}$ Published with the aid of a grant from the Museum of Comparative Zoology at Harvard College.
} 
of the species. The antennae of the female are $3.7 \mathrm{~mm}$. long. Each consists of 42 segments, instead of 60 as in the male, and the individual segments are smaller than in the male. The hairs on the antennal segments are shorter than those of the male and form a different pattern (figure I). A ring of twelve conspicuous setae is located near the distal end of each segment and two prominent hairs occur on one side of each segment, slightly distal of the ring just mentioned; these two hairs are a little longer than the hairs comprising the ring and they almost always project in the same direction, as shown in figure Ia. The more proximal part of each antennal segment includes about 20 short hairs which are arranged somewhat irregularly and which do not form a second ring, as in the male. The ovipositor of the female is like that of other Inocellia; in the specimen at hand it is $5.5 \mathrm{~mm}$. long. The body length of the female, exclusive of the antennae and ovipositor, is $6 \mathrm{~mm}$.

It seems virtually certain that this new female, which was collected at Chipinguy Mesa, near Monterrey, Nuevo Leon, Mexico, July 28, 1960, belongs to pilicornis. A male, collected by Dr. Howden at the same time, is like the holotype, except that the white markings on the abdominal tergites are somewhat smaller.

Although the female turns out to have antennal characteristics as distinctive as those of the male, I do not believe that a new genus is necessary for this species. Other features, including the abdominal structures of the male and female, are similar to those of other species of Inocellia. 

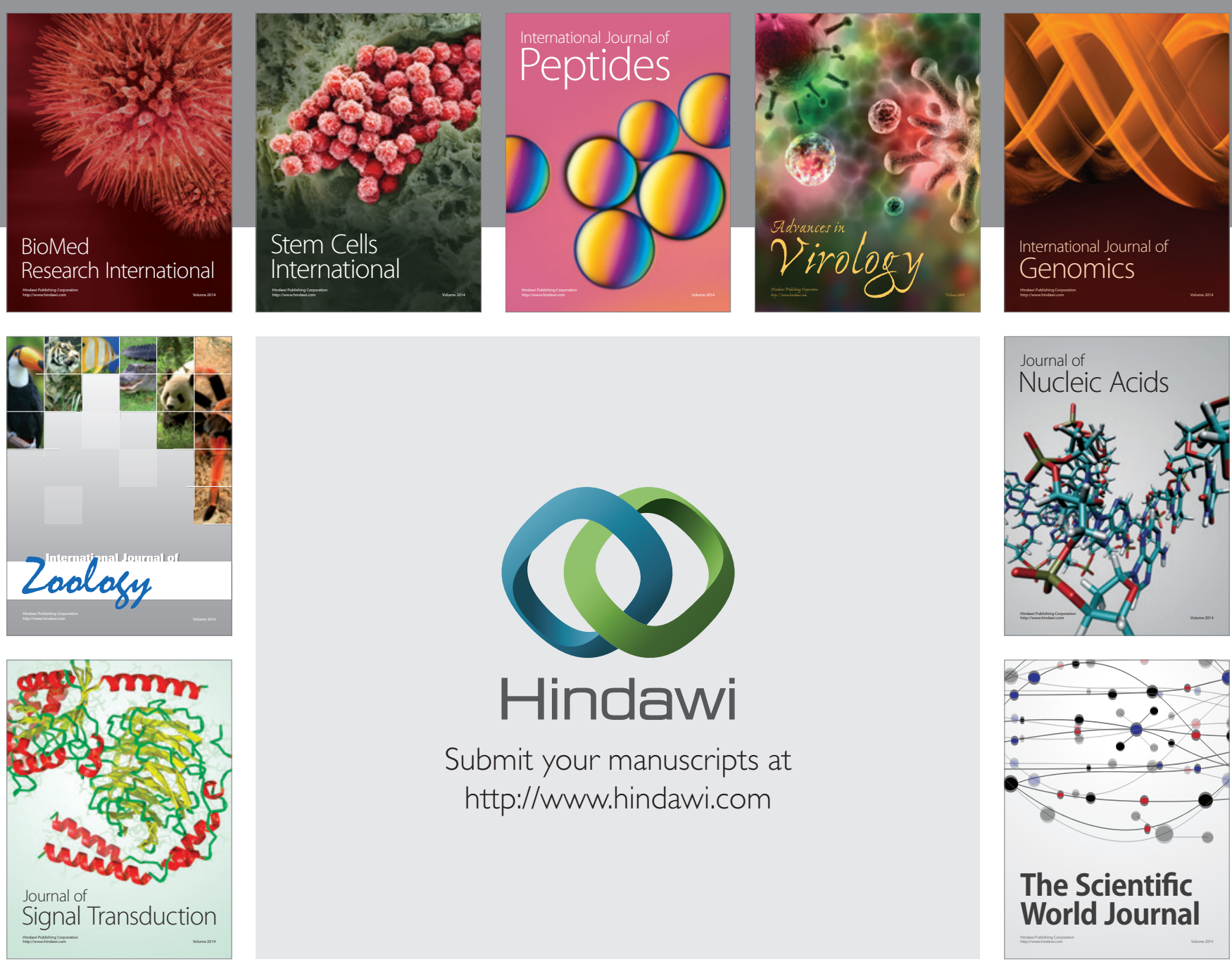

Submit your manuscripts at

http://www.hindawi.com
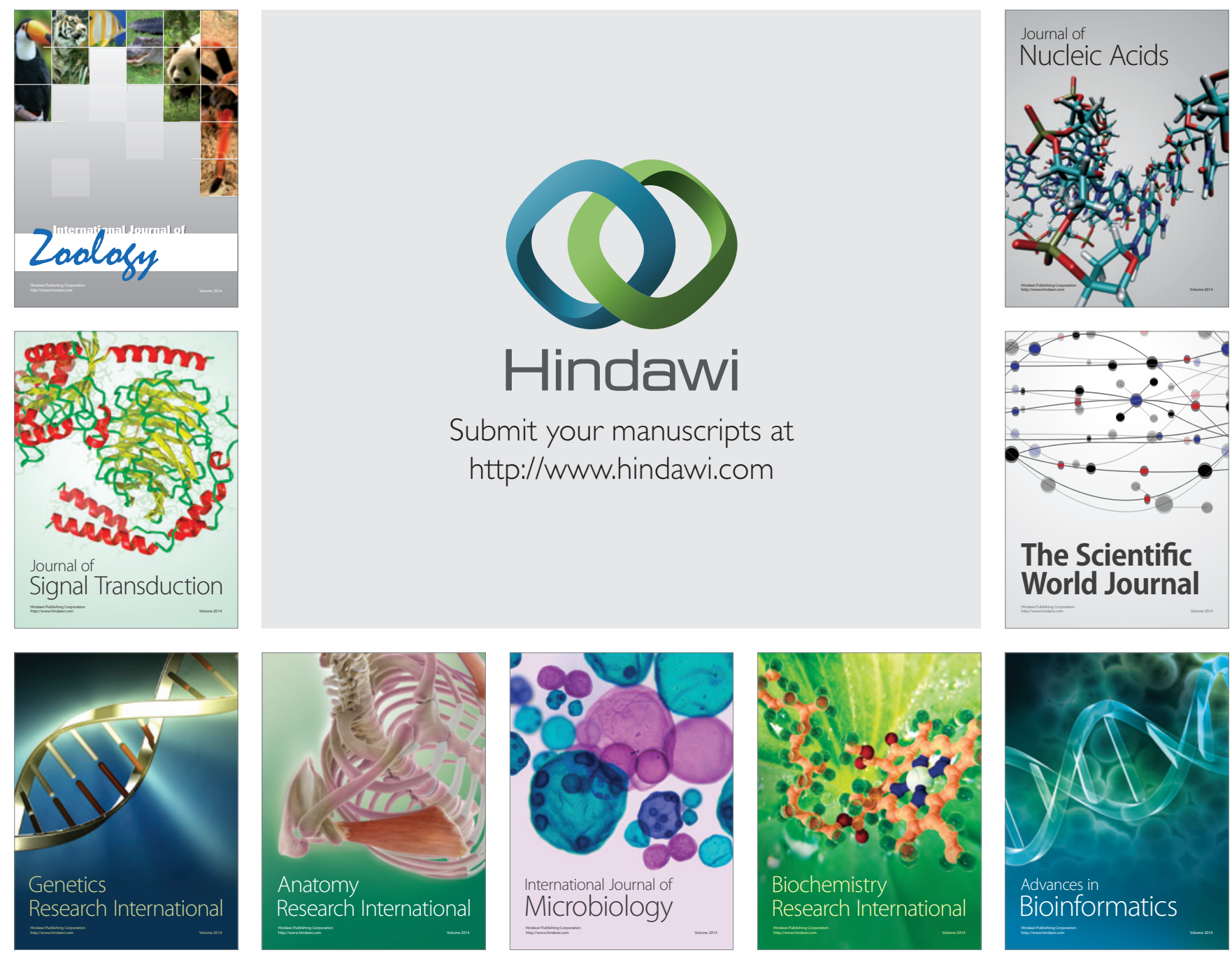

The Scientific World Journal
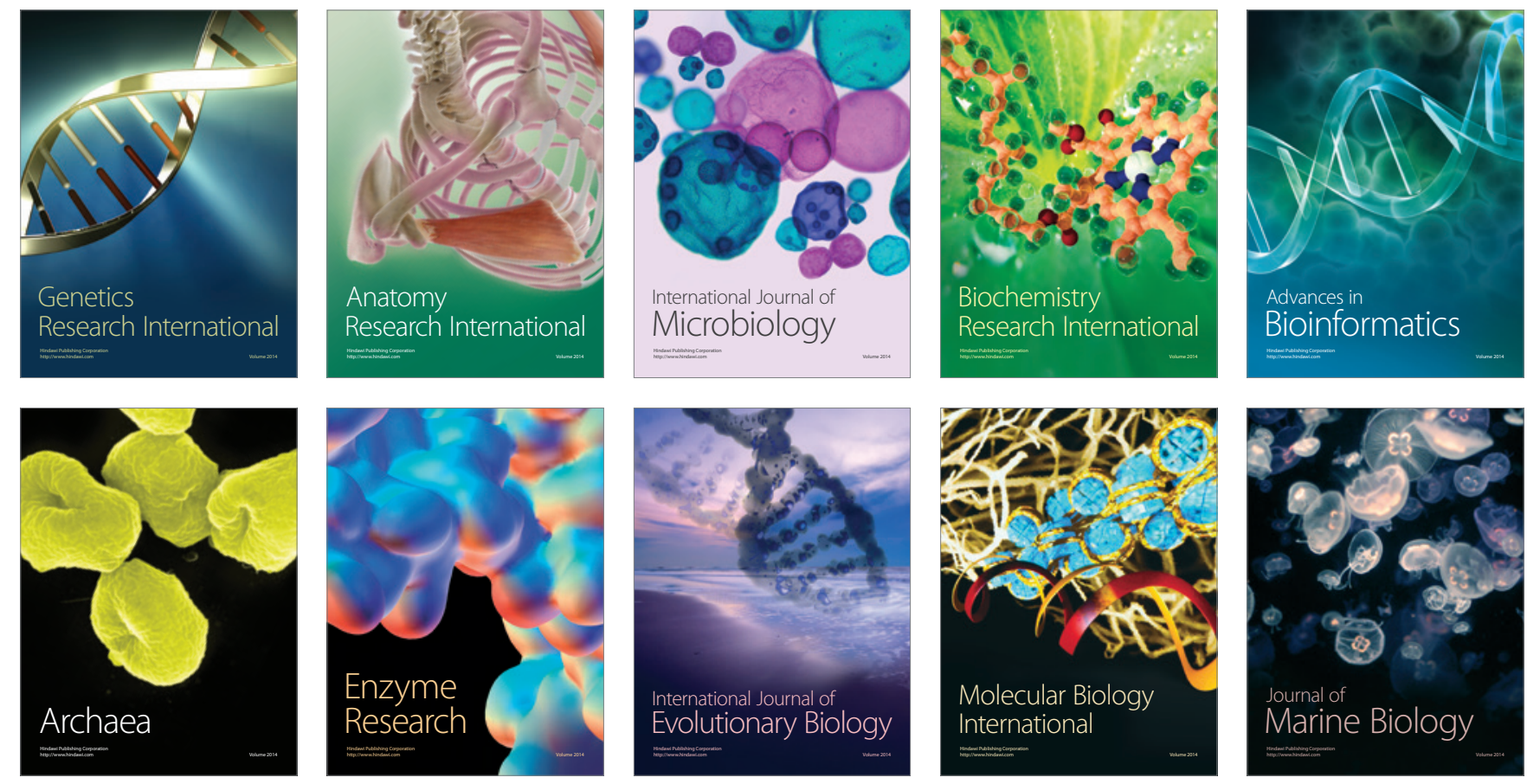